\title{
AVALIAÇÃO DE FONTES DE INFORMAÇÃO NA INTERNET: AVALIANDO O SITE DO NUPILL/UFSC
}

\author{
Rodrigo de Sales \\ Patrícia Pinheiro de Almeida
}

\section{Resumo}

O artigo apresenta alguns critérios de avaliação de fontes de informação, sobretudo na Internet, extraídos da literatura recente das áreas da Ciência da Informação e Engenharia de Produção. Descreve significativas transformações ocorridas na maneira do homem construir e difundir o conhecimento, ações que estão diretamente ligadas às fontes de informação, que por sua vez estão atreladas ao desenvolvimento da ciência e da tecnologia. Ressalta a necessidade de avaliação das fontes de informação na sociedade atual que, impulsionada pelo rápido desenvolvimento nas tecnologias de informação e comunicação, vê-se envolvida por uma imensurável quantidade de fontes de informação disponíveis em rede. Apresenta uma avaliação realizada no site e nas fontes de informação do NUPILL/UFSC, com base em critérios extraídos da literatura. Constata que o site e as fontes de informação avaliados neste artigo estão predominantemente adequados segundo o modelo de critérios eleito pelos autores como o mais completo.

\section{Palavras-chave}

Fontes de informação; Avaliação-fontes de informação; Critérios de avaliação; NUPILL/UFSC

\section{EVALUATION OF INFORMATION SOURCES ON THE INTERNET: EVALUATING NUPILL/UFSC SITE}

\begin{abstract}
This article presents some criteria for evaluating sources of information, above all on the internet, extracted from the recent literature in the areas of Communication Sciences and Production Engineering. Describes significant transformations that have occurred in the way that man constructs and disseminate knowledge, actions that are directly connected with the sources of information, which in turn are linked to scientific and technological development. Makes evident the necessity of information sources evaluation in the current society that, stimulated by the rapid development of information and communication technologies, find itself involved by an immeasurable quantity of information and sources available on the net. Presents an evaluation made on the site and information sources of NUPILL/UFSC, based on criteria extracted from the literature. It is evidenced that the site and its information sources evaluated in this article are predominantly adequate, according to the models of criteria chosen by the authors as the most complete.
\end{abstract}

\section{Keywords}

Information sources; Evaluation-information sources; Evaluation criteria; NUPILL/UFSC 


\section{INTRODUÇÃO}

É possível ver através da história que o conhecimento é elemento fundamental na sobrevivência das espécies. Dos ancestrais do homem, há aproximadamente 100 mil anos atrás, até a civilização pós-moderna o homem utiliza o conhecimento (o conhecimento aqui referido diz respeito àquilo que é conhecido, e não necessariamente o conhecimento científico, que é caracterizado por sua elaborada complexidade) para suprir suas necessidades de sobrevivência. São as necessidades que desenvolvem o conhecimento, pois são questões não resolvidas, perguntas sem respostas, que levam o homem a construir soluções. A necessidade de se alimentar e de se proteger fez os ancestrais do homem desenvolverem as primeiras armas de caça e as primeiras vestimentas de nossa história, assim como a necessidade de se comunicarem os levaram a desenvolver as primeiras formas de expressão humana. Com o passar dos tempos as necessidades dos homens foram se transformando, conseqüentemente foram se transformando também a realidade construída por eles. Na sociedade atual as necessidades são outras, mas continuam dependentes do conhecimento produzido e consumido pelo homem.

O conhecimento não existe se não houver uma fonte, uma origem, de informação que fornece subsídios para sua construção. Tem-se que durante todo o processo histórico do desenvolvimento do conhecimento o homem dependeu das fontes de informação, que se transformaram e continuam se transformando até hoje. O desenvolvimento exponencial ocorrido nas tecnologias de informação e comunicação potencializa o surgimento, cada vez mais rápido, de fontes de informação. Tal fato traz consigo a necessidade de esforços que visem à avaliação da qualidade dessas fontes. É nesse viés que o presente artigo apresenta uma avaliação realizada em uma fonte de informação disponível na rede mundial de computadores (Internet).

Primeiramente são apresentadas algumas transformações significativas no decorrer da história relacionadas com a construção e difusão do conhecimento, que estão diretamente ligadas às fontes de informação. Em seguida, focando a questão da avaliação 
de fontes de informação, sobretudo na Internet, são apresentados alguns critérios de avaliação extraídos da literatura. Num terceiro momento são descritas as etapas de uma avaliação realizada no site do Núcleo de Pesquisa em Informática, Literatura e Lingüística da Universidade Federal de Santa Catarina - NUPILL/UFSC.

\section{TRANSFORMAÇÕES NA CONSTRUÇÃO E NA DISPONIBILIZAÇÃO DO CONHECIMENTO}

O comportamento humano pode não estar num constante processo de evolução, mas está constantemente sendo transformado, o que permite afirmar que o homem vive num constante processo de transformação. Esse processo de transformação do comportamento humano, que é denominado por Elias (1994) como processo civilizador, está diretamente ligado à “troca de conhecimento”. Essa troca de conhecimento é factível através das mais variadas formas, desde uma despropositada conversa até a formalização do conhecimento registrado em um livro.

Elias (1994) menciona que pode parecer um esforço desnecessário para a civilização atual um autor se dedicar a escrever manuais de como um garoto deve se comportar na mesa durante uma refeição. Porém, o conceito que se tem nos dias atuais com relação ao termo ‘civilização' sofreu significativas transformações desde os séculos XVII e XVIII, em que esses tipos de escritos eram fontes preciosas de informação, sobretudo para as famílias pertencentes à nobreza européia. Assim como o conceito (significado) do termo (significante) civilização sofreu grande transformação no decorrer dos séculos, o conhecimento humano também se transformou, e se transforma, de acordo com a realidade do homem. A História documenta que foram muitas as transformações no modo de construir e distribuir conhecimento. Dos homo-sapiens (mais de 100 mil anos atrás), que desenvolviam sua capacidade de pensamento para suprir necessidades de comer e se proteger, até o homem pós-moderno, imerso em uma infinidade de informações, ou seja, dos tempos das cavernas aos tempos da Internet, houve uma enorme transformação no modo como o homem busca e produz conhecimento. Considerando que o processo de 
produção de informação está diretamente ligado ao uso que se faz do conhecimento, a busca por informação em prol da produção de nova informação se transformou de forma significativa no decorrer da história da humanidade.

Meis (2002), sintetizando a mudança na construção e na transmissão do conhecimento na história da humanidade, inicia seu pensamento na era primitiva com as diferentes ações dos artesãos e dos sacerdotes. Enquanto os primeiros lançavam mão da praticidade do funciona-não-funciona para materializar o conhecimento e para servir de maneira útil e prática o povo de sua época, os sacerdotes se embasavam na racionalidade ao tentar explicar os acontecimentos da natureza e do homem através do Divino, saciando angústias e necessidades de conhecimento daquele povo. Esse modo de construir conhecimento foi significativamente transformado com os filósofos gregos a partir do final do século VI a.C, que, segundo Meis (2002) foram os primeiros a usarem a lógica e a observação para interpretar a natureza. Desses filósofos, denominados naturalistas, destacase Aristóteles, que postulou novidades nas mais variadas áreas do saber através da observação e da lógica. Para Meis (2002), os mitos do sobrenatural também exerceram forte influência na construção do conhecimento, chegando a distorcer, em tempos mais recentes, o raciocínio dos pensadores e da população do século XVI.

Após os filósofos gregos, uma mudança marcante no processo de construção do conhecimento ocorreu nos séculos XV e XVI com os pensadores experimentalistas, como Leonardo da Vinci e Galileu Galilei. A busca da comprovação através de experiências para dar veracidade às interpretações lógicas, característica principal dos experimentalistas, trouxe de volta a prática do funciona-não-funciona iniciada pelos artesãos da era primitiva. Porém, os experimentalistas aplicavam suas investigações sob o controle de critérios e métodos, ou seja, o rigor investigativo dos experimentalistas transformou o funciona-nãofunciona dos artesãos em prática científica. Para Meis (2002), da Vinci e Galilei faziam uso de raciocínio matemático em seus experimentos, ou seja, lançavam mão da razão e da experiência para buscar comprovações. A idéia de que a comprovação legitima a interpretação e a observação foi ao longo dos anos sendo construída por teóricos defensores 
do experimentalismo - haja vista da Vinci, Galilei, Kepler, Copérnico, Francis Bacon - e definitivamente consolidada com o método de René Descartes. É aproximadamente nesse período da história humana que surgem as academias de ciências, como a Academia de Galileu Galilei na Itália (1560), Royal Society of London na Inglaterra (1645) e a Academia Francesa (século XVII). Tem-se nesse momento a institucionalização da ciência.

Apesar da imprensa de Gutenberg, surgida no século XV, ter provocado um significativo aumento na produção e na distribuição dos registros de conhecimento (informação), foi no período Pós Segunda Guerra (1945) que os países desenvolvidos começaram a investir maciçamente em tecnologias de informação e comunicação. Esse fato impulsionou a grande explosão da informação, transformando mais uma vez o modo de construir e distribuir informação. Segundo Cendón (2003) foi na década de 1960, durante a Guerra Fria, que o Departamento de Defesa do governo norte-americano iniciou a criação de uma rede experimental de computadores com o intuito de potencializar estratégias de guerra, o que resultou na criação da Advanced Research Projects Agency Network (ARPANET) em 1975. Pode-se afirmar que o Projeto ARPANET foi o precursor da Rede Internacional de Computadores (Internet). Utilizada inicialmente para fins científicos e acadêmicos, a Internet surgiu para a população mundial há aproximadamente vinte anos atrás, e revolucionou o processo de busca de informação. Assim como o impacto causado pelo surgimento da imprensa, do telefone, do rádio e da televisão, a Internet transformou de maneira significativa o comportamento do homem e sua relação com a informação. À Internet vem agregada a possibilidade de conexão mundial via computadores.

Com a Internet, surge também o desenvolvimento de recursos informáticos possíveis no meio digital. O hipertexto é um exemplo desses recursos, ele possibilita uma leitura repleta de conexões. Um texto não necessita mais ser lido de maneira linear como ocorre nas leituras realizadas no meio impresso. O hipertexto, através de suas hiperligações, permite que o leitor elabore sua própria estratégia de leitura, percorrendo o caminho que achar mais conveniente. O leitor do hipertexto se transforma em autor através de suas escolhas, como afirma Bellei (2002), o leitor se transforma em lautor, ou então como 
afirma O zapear de Blattmann e Fragoso (2003), o leitor se transforma em zapeador. O lautor de Bellei é o leitor-autor, aquele que compõe o texto conforme sua ação de leitura, e, o zapeador de Blattmann e Fragoso é o sujeito que navega pela teia da Internet explorando os recursos por ela proporcionados. O hipertexto é um exemplo categórico de que mais uma vez o homem está transformando sua maneira de buscar e construir conhecimento e, conseqüentemente, informação (e vice-versa), através da realidade tecnológica que o cerca.

Em se tratando de busca de informação, não se pode deixar de mencionar a importância irrefutável das fontes de informação que, com o advento da Internet, se tornaram imensurável. É devido a esse grande número de fontes de informação disponíveis na Rede, que se tornou imprescindível a elaboração de critérios que avaliem a qualidade das fontes. Na próxima seção serão abordados alguns estudos referentes a esses critérios.

\section{CRITÉRIOS DE AVALIAÇÃO DE FONTES DE INFORMAÇÃO}

Todo conhecimento advém de uma fonte de informação. Para criar um novo conhecimento é imprescindível que este seja embasado por outro conhecimento já existente e devidamente comunicado em alguma fonte de informação, seja ela oral, escrita ou áudiovisual. Por exemplo, um cientista pode estar realizando uma experiência inédita em laboratório, mesmo assim ele estará constantemente recorrendo a fontes de informação que lhe forneçam suportes metodológicos, ou teóricos, ou práticos. Também poderia estar um escritor elaborando um romance nunca antes imaginado e publicado, porém o uso da linguagem que ele fará para expressar sua ficção advém de um conhecimento préestabelecido. Portanto, a criação de novos conhecimentos está diretamente ligada a fontes de informação.

Em decorrência do exponencial desenvolvimento das tecnologias utilizadas para informar, as fontes estão cada dia, mais presentes na rede internacional de computadores. Tal fato faz aumentar o acesso às respectivas fontes, transformando consideravelmente o comportamento do homem ao buscar e disponibilizar informação. Segundo Silva e Tamaél 
(2004) esta mudança, que altera significativamente o mercado de trabalho, abarca todos os segmentos da sociedade atual, econômico, político, científico e cultural. É importante ressaltar que o presente artigo está focando sobretudo o segmento científico e acadêmico.

Com o maior acesso às fontes de informação viabilizadas pela Internet, e principalmente, devido ao fato dessas fontes geralmente não serem submetidas a uma avaliação prévia, acarretando em disponibilização de informações irrelevantes, impertinentes, imprecisas e desatualizadas, faz-se indispensável a realização de um estudo referente aos critérios de avaliação de fontes de informação disponíveis na Internet. Tomaél et al. (2004) afirmam que “a importância de avaliar-se a informação disponível na Internet é bastante significativa para quem a utiliza com a finalidade [de] pesquisa, e é de extrema relevância para enfatizar a inconstância da qualidade das informações encontradas” (TOMAÉL et al., 2004, p.19). Apesar da grande quantidade, a localização de uma fonte de informação específica e eficiente na Internet pode ser uma difícil tarefa para aqueles que não levam em consideração critérios de qualidade e aspectos relacionados ao custo de busca e obtenção da informação. Segundo Tomaél et al. (2004), custo de acesso, custo de uso, custo de serviços diferenciados, energia e tempo, são exemplos de custos referentes à busca e obtenção de informações na Internet.

Em estudo realizado com o objetivo de avaliar uma fonte de informação (base de dados) da área de engenharia civil disponível em CD-ROM ${ }^{1}$, Tristão (1996) faz uso de critérios referentes à relevância dos documentos recuperados e do aspecto de cobertura. Para Tristão (1996, p. 35) "relevância é definida como a capacidade do sistema de [fornecer] respostas (referências) que correspondam à questão proposta”. Segundo Lopes apud Tristão (1996), para avaliação de fontes de informação, a cobertura é um dos mais relevantes critérios, pois se preocupa com a abrangência da literatura da área de domínio.

\footnotetext{
${ }^{1}$ Embora não se tratando, até a data da pesquisa, de uma fonte disponível na Internet, a autora lançou mão de critérios utilizados atualmente para avaliar fontes on-line.
} 
Parizotto (1997) realizou um estudo para elaborar um guia de estilos destinado a projetistas de sites acadêmicos e de ciência e tecnologia. Estes tipos de sites são fontes de informação constantemente utilizadas não somente por membros da comunidade acadêmica, mas também por pesquisadores e profissionais dos mais variados segmentos. Para o referido estudo, Parizotto (1997) focou aspectos gráficos, dando ênfase ao projeto visual, tais como: layouts, cores, fundos, fontes, textos e ícones. A autora afirma que o layout de uma página na Internet não exerce apenas uma função estética, mas principalmente influencia a maneira como o usuário percebe e sente a informação ali disponível. Funciona como uma importante ferramenta para auxiliar a comunicação escrita. Parizotto (1997) disserta também a respeito das vantagens e desvantagens referentes ao uso das cores em uma página da Internet, atribuindo-as grande importância. Com relação ao fundo, a pesquisadora afirma que "a escolha do fundo desempenha um papel muito importante no resultado final de uma página. Ele pode aumentar o interesse do projeto visual” (PARIZOTTO, 1997, p. 47). O fundo é a composição de padrões de textura e cores. As fontes estão intimamente atreladas à legibilidade do texto. Os ícones são, segundo Parizotto (1997), guias funcionais e estéticos para as interfaces gráficas que interagem com os usuários, e tem como função representar objetos ou tarefas. Assim como Parizotto (1997), Tomaél et al. (2004) descrevem os dez erros no desenvolvimento de projetos de páginas na Internet segundo os escritos de Jakob Nielsen, a saber: uso de frames, tecnologia inadequada devido a facilidade de aquisição, páginas muito longas, excesso de animações, URLs complexas, páginas soltas, falta de apoio para navegação, links sem padronização de cores, informação desatualizadas e páginas que demoram muito tempo para carregar.

Em trabalho realizado com o intuito de avaliar a qualidade de informação disponibilizada na World Wide Web na área da saúde, Lopes (2004) afirma que o advento das tecnologias da informação e da comunicação está possibilitando que qualquer pessoa com acesso à Internet exponha seus trabalhos sem nenhum, ou quase nenhum, controle profissional, o que compromete significativamente a qualidade do conteúdo da informação disponibilizada. É necessário ressaltar que nas fontes de informação (pelo menos nas mais conceituadas) de âmbito científico a avaliação dos pares se faz presente, zelando assim pelo 
conteúdo da informação disponibilizada. A autora faz uso dos critérios de avaliação recomendados pelo grupo de trabalho Health Summit Working Group (HSWG) para avaliar a qualidade de informação na área da saúde disponível na WEB. Os critérios categorizados como indicadores de qualidade pelo HSWG são os seguintes: credibilidade, conteúdo, apresentação formal do site, links, design, interatividade e anúncios. Para o indicador de credibilidade o HSWG avalia os aspectos de fonte, contexto, atualização, pertinência e processo de revisão editorial. Para o indicador de conteúdo são avaliados a acurácia, a hierarquia de evidência, a precisão das fontes, os avisos institucionais e a completeza. Para a apresentação formal do site são observadas as apresentações dos objetivos e do perfil da página. Com relação aos links são avaliados a seleção, a arquitetura, o conteúdo e a opção de retorno. O design contempla a acessibilidade, a navegabilidade e o mecanismo de busca interna. A interatividade se ocupa em verificar o mecanismo de retorno da informação, fórum de discussão e a explicitação de algoritmos. Os anúncios se atêm aos alertas existentes nos sites.

Apresentando estratégias ao usuário em sua relação com acervos qualitativos onlines, e recomendando critérios de avaliação de documentos disponíveis na Internet, Pinto et al. (2004) realizaram um estudo focando o uso da Internet por membros acadêmicos das áreas de Engenharia Civil, Educação Física e Administração. Nesse estudo, as autoras, pautadas pela literatura, afirmam que para uma adequada avaliação de fontes de informação disponível na Rede é necessário adotar critérios que abordem os seguintes aspectos: "autoridade, escopo, cobertura/conteúdo, público alvo, proposta da informação, acesso/endereço do documento, corpo editorial, e atualidade” (PINTO et al., 2004, p.147).

Tomaél et. alii (2004), tratando a análise da qualidade de fontes de informação na Internet, mencionam um tutorial on-line e interativo voltado a questões de qualidade de fontes de informação na Rede - o Internet Detective. O referido tutorial classifica três grupos de critérios: conteúdo, forma e processo. O grupo referente ao conteúdo é avaliado sob os seguintes aspectos: validade, precisão, autoridade e reputação da fonte, singularidade, completeza e cobertura. Para os critérios referentes à forma são avaliados os 
seguintes itens: características de navegação, suporte ao usuário e utilização de tecnologias apropriadas. Os critérios de processo são os seguintes: integridade da informação, integridade do site e integridade do sistema.

Após exaustivos estudos teóricos e de pesquisas em páginas da Internet, acompanhados de testes em projeto piloto, Tomaél et al. (2004) apresentam dez itens pormenorizados em subitens destinados à avaliação de fontes de informação na Internet. Para melhor visualizar os critérios pontuados pelos autores, optou-se pela elaboração de um quadro (Quadro 1 abaixo) que visa facilitar a compreensão dos referidos itens.

Quadro 1 - Critérios de Qualidade para Avaliar Fontes de Informação na Internet

\begin{tabular}{|c|c|}
\hline Critérios & Subcritérios \\
\hline Informação de Identificação & $\begin{array}{ll}\text { - } & \text { Endereço eletrônico do site e da fonte de informação } \\
\text { - } & \text { E-mail do site (organização que disponibiliza a fonte) } \\
\text { - } & \text { Título da fonte de informação } \\
\text { - } & \text { Endereço eletrônico da fonte de informação } \\
\text { - } & \text { Objetivos da fonte e a que público se destina } \\
\text { - } & \text { Disponibilização de informações adequadas sobre a fonte } \\
\text { - } & \text { Identificação da tipologia da fonte e de sua origem }\end{array}$ \\
\hline Consistência das Informações & $\begin{array}{ll}\text { - } & \text { Cobertura da fonte } \\
\text { - } & \text { Validez do conteúdo } \\
\text { - } & \text { Resumos ou informações complementares } \\
\text { - } & \text { Coerência na apresentação do conteúdo informacional } \\
\text { - } & \text { Oferta de informações filtradas ou com agregação de valor } \\
\text { - } & \text { Apresentação de informação original }\end{array}$ \\
\hline Confiabilidade das Fontes & $\begin{array}{l}\text { - } \quad \text { Dados completos de autoria (como mantenedor) } \\
\text { - } \quad \text { Autoria reconhecida em sua área de atuação } \\
\text { - } \quad \text { Organização que disponibiliza o site } \\
\text { - } \quad \text { Conteúdo informacional relacionado com a área de atuação do } \\
\text { autor } \\
\text { - Observância de outras informações como: referências } \\
\text { bibliográficas dos trabalhos do autor; endereço para contato com } \\
\text { autor; origem da informação. } \\
\text { - Verificação de datas }\end{array}$ \\
\hline
\end{tabular}


Links

Facilidade de Uso

Layout da Fonte

Restrições Percebidas
- Links internos

- clareza para onde conduzem

- tipos disponíveis

- atualização dos links

- Links externos

- clareza para onde conduzem

- devem apontar apenas para sites confiáveis

- tipos disponíveis mais comuns: informações complementares, ilustrações, portais temáticos, etc

- revisão constante dos links

- $\quad$ Links

- que possibilitem fácil movimentação

- que possibilitem avançar e retroceder

- Quantidade de cliques para acessar a fonte e a informação

- da página inicial até a fonte são recomendados três cliques

- da fonte à informação são três ou menos cliques

- Disponibilidade de recursos da pesquisa na fonte

- função de busca

- lógica booleana

- índice

- arranjo

- outros

- Recursos auxiliares à pesquisa

- tesauros, listas, glossários, mapa do site, guia, ajuda na pesquisa, outros

- instruções de uso

- manuais da fonte de informação para download ou impressão

- As mídias utilizadas devem ser interessantes

- Tipos de mídias utilizadas

- A harmonia entre a quantidade de mídias

- Coerência entre as várias mídias

- imagens com função de complementar o conteúdo e não apenas ilustrar

- pertinência com os propósitos da fonte

- legibilidade

- clara identificação das imagens

- Na estrutura do layout e arranjo é importante que:

- haja coerência na utilização de padrões

- os recursos sirvam a um propósito e não apenas decoração

- as imagens facilitem a navegação

- o design do menu seja estruturado para facilitar a busca

- a criatividade contribua para a qualidade

- evite-se o frame, que limita o uso da fonte

- Pequena quantidade de acessos simultâneos

- Alto custo de acesso à fonte de informação

- Mensagens de erro durante a navegação 


\section{ARTIGO}

- Direitos autorais impedindo o acesso à informação completa

Suporte ao Usuário

Outras Observações Percebidas
- Contato com o produtor da fonte

- Informações de ajuda na interface

- Recursos que auxiliam o deficiente no uso da fonte

- Opção de consulta em outras línguas

Fonte: Elaborado pelos autores deste artigo apoiados em: Tomaél et al. (2004).

Outro trabalho referente à avaliação de fontes de informação na Internet que merece destaque é o artigo de Simão e Rodrigues (2005), que comunica parte da Dissertação de Mestrado de Simão defendida em 2004 na Universidade de Brasília. Propondo-se a avaliar o Portal de serviços e informações do governo brasileiro (Portal Rede Governo), os autores utilizam a metodologia empregada por Vilella apud Simão e Rodrigues (2005), que examina três dimensões de avaliação, o conteúdo, a usabilidade e a funcionalidade. Essas três dimensões são divididas em 14 parâmetros: abrangência/cobertura e propósito, atualidade, metadados, correção, autoridade/copyright, objetividade, inteligibilidade, apreensibilidade, operacionalidade, adequação, acurácia, interoperabilidade, conformidade e segurança de acesso (VILELLA apud SIMÃO e RODRIGUES, 2005, p. 84). Estes por sua vez estão agrupados em 73 critérios (para ter acesso aos 73 critérios consulte o artigo de Simão e Rodrigues disponível em: http://www.ibict.br/cienciadainformacao/viewarticle.php?id=721\&layout=html).

Com o exposto nesta seção, fica claro que são vários os trabalhos voltados à avaliação de fontes de informação, e que embora haja critérios de avaliação diferentes em cada pesquisa, aspectos como autoridade, cobertura/abrangência, conteúdo, confiabilidade, atualização e usabilidade são itens convergentes nos respectivos trabalhos. 


\section{AVALIAÇÃO DO SITE DO NUPILL/USFC}

\subsection{O NUPILL/UFSC}

O Núcleo de Pesquisas em Informática, Literatura e Lingüística - NUPILL está vinculado ao Curso de Pós-Graduação em Literatura Brasileira, do Centro de Comunicação e Expressão da Universidade Federal de Santa Catarina. O NUPILL tem como proposta central o desenvolvimento de pesquisas sobre os textos literários em meio digital, abrangendo uma gama que vai da criação à leitura utilizando dispositivos e processos da informática, passando por estratégias e ferramentas de ensino e aprendizagem de Literatura, assim como das práticas de produção de textos. A vocação do NUPILL é, assim, explorar os recursos que a informática e as tecnologias da informação e da comunicação trazem para a pesquisa universitária, em particular no domínio das Letras, tanto em Literatura quanto em Lingüística.

Dentre os projetos do NUPILL os de maior projeção e visibilidade acadêmicas são os Banco de Dados de História Literária e a Biblioteca Digital de Literatura Brasileira (disponíveis na URL http://alecrim.inf.ufsc.br/bdnupill/), que são as fontes de informação avaliadas neste artigo, juntamente à avaliação do site www.nupill.org , que, embora já esteja disponível na Internet, está em fase final de atualização, e em breve será o site oficial do NUPILL. O site do NUPILL disponibiliza além de informações relacionadas ao próprio Núcleo, como apresentação, missão, objetivos, equipe, projetos (destaque para o banco de dados e para a biblioteca digital), criações textuais e hipertextuais, periódicos e bibliografias, disponibiliza também links para Eventos da área e grupos de pesquisa cuja parceria se faz presente. O Banco de Dados de História Literária conta atualmente (dados atualizados em 15.05.2006) com dados bibliográficos de mais de 49.100 obras e dados biográficos de mais de 13.600 autores. O acervo da Biblioteca Digital contempla mais de 830 arquivos em texto completo, e podem ser salvas ou impressas sem restrições. Ressaltase que as obras disponíveis na Biblioteca Digital respeitam a Lei de Direitos Autorais Brasileira (Lei $n^{\circ}$ 9.610/98). 


\subsection{Aplicação da avaliação do site e das fontes de informação do NUPILL.}

Para a avaliação do site do NUPILL e das fontes de informação nele contidas (Banco de Dados de História Literária e Biblioteca Digital de Literatura Brasileira) optouse em adotar os critérios pontuados por Tomaél et. alii (2004), devido à exaustiva pesquisa realizada pelos autores, e aos testes efetuados com esses critérios.

A primeira etapa da avaliação consistiu em navegar pelo site e pelas fontes de informação verificando a existência ou não dos critérios e subcritérios descritos no Quadro 1 exposto na Seção 3 deste artigo. Cabe ressaltar que os critérios de Tomaél et al. (2004), contidos no referido quadro, servem para avaliar sites e fontes de informação contidas nos sites, o que permitiu utilizar o mesmo quadro para a avaliação simultânea do site, do banco de dados e da biblioteca digital.

Na segunda etapa foram determinados códigos e conceitos para efetuar a aplicação do Quadro 1. Determinou-se que a letra “A” representaria adequação do critério; a letra "I” inadequação do critério; o código "A/I" adequação parcial do critério; o código "A/I +" adequação parcial, porém com mais itens atendidos do que não atendidos; o código "A/I -” adequação parcial, porém com menos itens atendidos do que não atendidos; e o código "--” inexistência do critério. Melhor dizendo: $\mathrm{A}$ = adequado; $\mathrm{I}$ = inadequado; $\mathrm{A} / \mathrm{I}$ = adequado parcialmente; $\mathrm{A} / \mathrm{I}+$ = adequado parcialmente para mais; $\mathrm{A} / \mathrm{I}$ - = adequado parcialmente para menos; -- = não existente. É importante ressaltar que para os itens divididos dentro de um subcritério foram utilizados os mesmos códigos, porém com letras minúsculas (ver Quadro 2).

Concluída a etapa de codificação, ou seja, determinados os códigos e seus significados, efetuou-se uma navegação detalhada no site aplicando os critérios do Quadro 1, conceituando cada critério e/ou subcritério de acordo com os códigos descritos acima (conforme exposto no Quadro 2 abaixo). 
Quadro 2 - Aplicação dos Critérios de Qualidade no Sirte e Fontes de Informação do NUPILL

\begin{tabular}{|c|c|}
\hline Critérios & Subcritérios \\
\hline $\begin{array}{l}\text { Informação de Identificação } \\
(\mathrm{A} / \mathbf{I}+)\end{array}$ & $\begin{array}{ll}\text { - } & \text { Endereço eletrônico do site e da fonte de informação (A/I) } \\
\text { - } & \text { E-mail do site (organização que disponibiliza a fonte) (I) } \\
\text { - } & \text { Título da fonte de informação (A) } \\
\text { - } & \text { Endereço eletrônico da fonte de informação (I) } \\
\text { - } & \text { Objetivos da fonte e a que público se destina (A/I) } \\
\text { - } & \text { Disponibilização de informações adequadas sobre a fonte (A) } \\
\text { - } & \text { Identificação da tipologia da fonte e de sua origem (A) }\end{array}$ \\
\hline Consistência das Informações (A) & $\begin{array}{ll}\text { - } & \text { Cobertura da fonte (A) } \\
\text { - } & \text { Validez do conteúdo (A) } \\
\text { - } & \text { Resumos ou informações complementares (A) } \\
\text { - } & \text { Coerência na apresentação do conteúdo informacional (A) } \\
\text { - } & \text { Oferta de informações filtradas ou com agregação de valor (A) } \\
\text { - } & \text { Apresentação de informação original (A) }\end{array}$ \\
\hline Confiabilidade das Fontes (A) & $\begin{array}{ll}\text { - } & \text { Dados completos de autoria (como mantenedor) (A) } \\
\text { - } & \text { Autoria reconhecida em sua área de atuação (A) } \\
\text { - } & \text { Organização que disponibiliza o site (A) } \\
\text { - } & \text { Conteúdo informacional relacionado com a área de atuação do autor } \\
\text { (A) } & \text { Observância de outras informações como: referências bibliográficas } \\
\text { - } & \text { dos trabalhos do autor; endereço para contato com autor; origem da } \\
\text { informação. (A) } & \text { - Verificação de datas (A) }\end{array}$ \\
\hline Adequação da Fonte (A) & $\begin{array}{l}\text { - Coerência da linguagem utilizada pela fonte, com relação aos } \\
\text { usuários e aos objetivos do site (A) } \\
\text { - Coerência com o propósito do site (A) }\end{array}$ \\
\hline Links (A/I) & $\begin{array}{ll}\text { - } & \text { Links internos (A/I) } \\
\text { - clareza para onde conduzem (a) } \\
\text { - tipos disponíveis (i) } \\
\text { - atualização dos links (a/i) } \\
\text { - } \quad \text { Links externos (A/I) } \\
\text { - clareza para onde conduzem (a) } \\
\text { - devem apontar apenas para sites confiáveis (a) } \\
\text { - tipos disponíveis mais comuns: informações (i) } \\
\quad \text { complementares, ilustrações, portais temáticos, etc } \\
\text { - } \quad \text { revisão constante dos links (i) }\end{array}$ \\
\hline Layout da Fonte (A) & $\begin{array}{ll}\text { - } & \text { As mídias utilizadas devem ser interessantes (A) } \\
\text { - } & \text { Tipos de mídias utilizadas (A) } \\
\text { - } & \text { A harmonia entre a quantidade de mídias (A) } \\
\text { - } & \text { Coerência entre as várias mídias (A) }\end{array}$ \\
\hline
\end{tabular}




\section{ARTIGO}

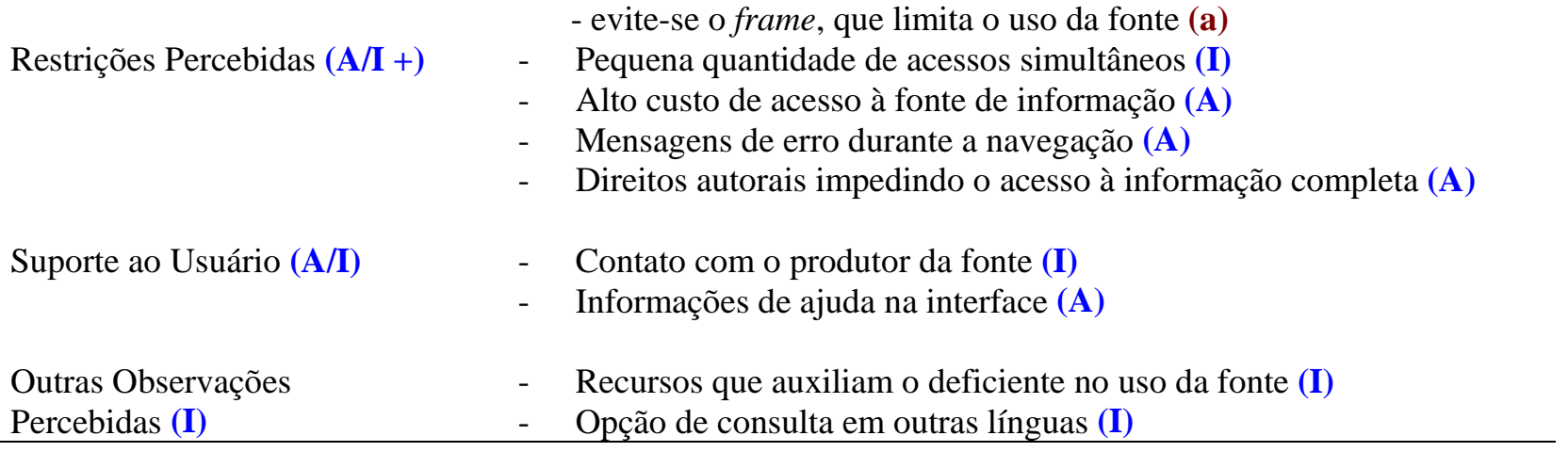

- evite-se o frame, que limita o uso da fonte (a)

- Pequena quantidade de acessos simultâneos (I)

- Alto custo de acesso à fonte de informação (A)

- Mensagens de erro durante a navegação (A)

- Direitos autorais impedindo o acesso à informação completa (A)

Percebidas (I)

- Opção de consulta em outras línguas (I)

- imagens com função de complementar o conteúdo e não apenas ilustrar (a)

- pertinência com os propósitos da fonte (a)

- legibilidade (a)

- clara identificação das imagens --

- Na estrutura do layout e arranjo é importante que: (A)

- haja coerência na utilização de padrões (a)

- os recursos sirvam a um propósito e não apenas decoração

- as imagens facilitem a navegação --

- o design do menu seja estruturado para facilitar a busca (a)

- a criatividade contribua para a qualidade --

A etapa seguinte foi elaborar um quadro (Quadro 3) que sintetizasse os resultados obtidos com a aplicação da avaliação. Os resultados foram sintetizados da seguinte maneira: suprimiu-se os conceitos individuais de cada subcritério lhes atribuindo uma média, ou seja, para um critério que obtivesse 02 subcritérios “A”, 01 subcritério “A/I” e 01 subcritério "I”, apresenta média final “A/I +” (adequação parcial para mais). O quadro abaixo (Quadro 3), permite a visualização sintetizada dos resultados obtidos. 
ARTIGO

Quadro 3 - Resultados da Avaliação do Site do NUPILL

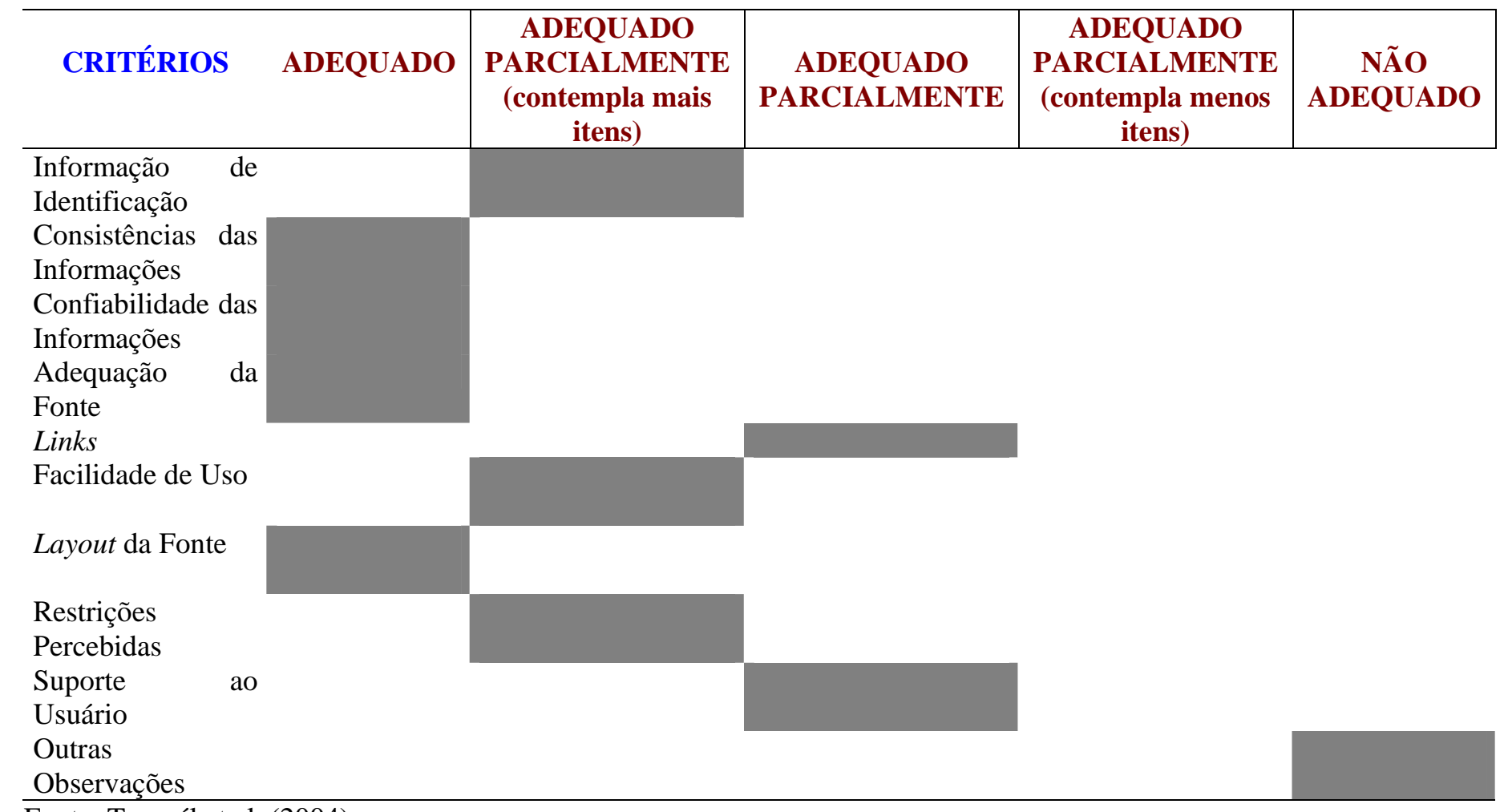

Fonte: Tomaél et al. (2004).

Com o exposto no quadro acima fica claro que, embora haja melhorias a serem feitas na disponibilização de informações no site do NUPILL (sobretudo nos aspectos referentes aos Links e ao Suporte ao Usuário, que apresentaram adequação parcial, e na possibilidade de consulta por parte de usuários portadores de deficiências e consulta em outras línguas - Outras Observações - que apresentaram inadequação), as fontes de informação disponíveis no respectivo site estão predominantemente adequadas aos critérios de qualidade pontuados por Tomaél et al. (2004).

\section{CONCLUSÕES E SUGESTÕES}

Com base na literatura referente à avaliação de qualidade de fontes de informação é possível concluir que com o rápido e vertiginoso desenvolvimento nas tecnologias de informação e comunicação, que viabiliza conexões internacionais em tempo real, as trocas 
de informação e conhecimento se tornam cada dia mais velozes. Este acesso imediato e rápido, possível àqueles que estejam conectados a Rede, potencializa a produção e o consumo de informação, porém, nem sempre efetuados de maneira que garanta a qualidade do que está sendo produzido e consumido. Muitas vezes a informação pode estar sendo disponibilizada e, conseqüentemente, utilizada com significativas inadequações, como por exemplo, informações desatualizadas, imprecisas e de conteúdo não confiável, além de morosidade no processo de busca da informação. Essas inadequações trazidas ao âmbito científico e acadêmico podem comprometer estudos e pesquisas de grande esforço e dedicação. Por isso, refletir e aplicar critérios que zelam pela qualidade das fontes de informação é um fazer imprescindível à comunidade científica responsável pela aproximação entre a realidade tecnológica e a realidade humana e social, que dependem diretamente da produção e consumo do conhecimento.

Quanto à aplicação realizada no presente estudo, enfatiza-se que os critérios pontuados por Tomaél et al. (2004) são apropriados não somente para avaliar o site e as fontes de informação do NUPILL, mas também para avaliar qualquer tipo de fonte de informação, sobretudo de caráter acadêmico e científico, disponível na Internet.

As fontes de informação disponíveis no site do NUPILL estão predominantemente adequadas quanto aos critérios de qualidade utilizados neste estudo, porém, necessitam ser melhoradas nos seguintes aspectos: links, suportes ao usuário, disponibilização de recursos que possibilite a consulta por parte de usuários portadores de deficiências e recursos que possibilite a consulta em outras línguas.

Investigações que comparem qualitativamente os modelos de avaliação apresentados neste artigo, juntamente com critérios de avaliação de fontes de informação encontrados em outros trabalhos da área, que visem à inferência de critérios não contemplados neste estudo, ou seja, que visem um modelo de avaliação criteriosamente mais detalhado, são sugestões para futuros trabalhos. 


\section{REFERÊNCIAS BIBLIOGRÁFICAS}

BELLEI, S. L. P. O livro, a literatura e o computador. São Paulo: EDUC; Florianópolis: EDUFSC, 2002, 169 p.

CENDÓN, B. V. A Internet. In: CAMPELO, B. S.; CEDON, B. V.; KREMER, J. M. (Org.). Fontes de informação para pesquisadores e profissionais. Belo Horizonte: Ed. da UFMG, 2000. p. 275-300.

ELIAS, N. O processo civilizador: uma história dos costumes. 2.ed. Rio de Janeiro: Jorge Zahar, 1994. 277p. v.1.

LOPES, I. L. Novos paradigmas para avaliação da qualidade da informação em saúde recuperada na Web. Ci. Inf., Brasília, v. 33, n. 1, p. 81-90, jan./abril 2004. Disponível em $<$ http://www.ibict.br/cienciadainformacao/viewarticle.php?id=54\&layout=abstract $>$ Acesso: 13 maio 2006.

MEIS, L. de. Ciência, educação e o conflito humano-tecnológico. 2.ed. São Paulo: SENAC São Paulo, 2002. 145 p.

NÚCLEO de Pesquisa em Informática, Literatura e Lingüística. Disponível em <http://www.nupill.org> Acesso em: 15 maio 2004.

BLATTMANN, U., FRAGOSO, G. M. (Org.). O zapear a informação em bibliotecas e na Internet. Belo Horizonte: Autêntica, 2003, 103 p.

PARIZOTTO, R. Elaboração de um guia de estilos para serviços de informação em ciência e tecnologia via Web. Florianópolis, 1997, 111 f. Dissertação (Mestrado em Engenharia de Produção) - Universidade Federal de Santa Catarina, Santa Catarina, 1997.

PINTO, M. D. de S. et al. Diversidade da recuperação de informações via Internet na pesquisa e ensino. Rev. ACB: Biblioteconomia em Santa Catarina, v. 8/9, p. 143-154, 2003/2004. Disponível em <http://www.acbsc.org.br/revista/ojs/viewarticle.php?id=98\&layout=abstract $>$ Acesso em: 15 maio 2006.

SILVA, T. E.; TOMAÉL, M. I. (Org.). Fontes de informação na Internet: a literatura em evidência. In: TOMAÉL, M. I.; VALENTIM, M. L. P. (Org.). Avaliação de fontes de informação na Internet. Londrina: Eduel, 2004. p. 01-17.

SIMÃO, J. B.; RODRIGUES, G. Acessibilidade às informações pública: uma avalição do portal de serviços e informações do governo federal. Ci. Inf., Brasília, v. 34, n. 2, p. 81-92, maio/ago.2005.

Disponível

em 
http://www.ibict.br/cienciadainformacao/viewarticle.php?id=721\&layout=html. $\quad$ Acesso em: 16 maio 2006.

TOMAÉL, M. I. et al. Critérios de qualidade para avaliar fontes de informação na Internet. In: TOMAÉL, M. I.; VALENTIM, M. L. P. (Org.). Avaliação de fontes de informação na Internet. Londrina: Eduel, 2004, p. 19-40.

TRISTÃO, A. M. D. Fontes de informação da área de engenharia civil: estudo da base de dados ICONDA. the international construction database. Florianópolis, 1996, $122 \mathrm{f}$. Dissertação (Mestrado em Engenharia de Produção) - Universidade Federal de Santa Catarina, Santa Catarina, 1996. 


\section{Rodrigo de Sales}

Mestrando em Ciência da Informação pela Universidade Federal de Santa Catarina (UFSC);

Bacharel em Biblioteconomia pela Universidade Federal de Santa Catarina (UFSC);

Bolsista (CNPq) do Núcleo de Pesquisa em Informática, Literatura e Lingüística (NUPILL/UFSC).

rodrigo biblio@yahoo.com.br

\section{Patrícia Pinheiro de Almeida}

Mestranda em Teoria Literária pela Universidade Federal de Santa Catarina (UFSC);

Bacharel em Comunicação Social - Jornalismo pelo Centro Universitário de Brasília Uniceub.

patvitara@hotmail.com 